\title{
Obesity and hypertensive heart disease: focus on body composition and sex differences
}

\author{
Giovanni de Simone ${ }^{1,2^{*}}$, Costantino Mancusi ${ }^{1,2}$, Raffaele Izzo ${ }^{1,2}$, Maria Angela Losi ${ }^{1,3}$ and L. Aldo Ferrara ${ }^{1}$
}

\begin{abstract}
There is evidence that hypertension is frequently associated with overweight/obesity even in kids and adolescents. Either conditions influence development of left ventricular (LV) hypertrophy (LVH), through different biological and hemodynamic mechanisms: obesity is conventionally thought to elicit a coherent growth of LV chamber dimensions and myocardial wall thickness (eccentric LV geometry), whereas a more accentuated increase in wall-thickness (concentric LV geometry) is attributed to hypertension. While during youth these differences are visible, proportion of LV concentric geometry, the most harmful LV geometric pattern, sharply raises in obese individuals during middle age, and becomes the most frequent geometric patterns among obese-hypertensive individuals. Two conditions with elevated hemodynamic impact, severe obstructive sleep apnea and masked hypertension contribute to the development of such a geometric pattern, but non-hemodynamic factors, and specifically body composition, also influence prevalence of concentric LV geometry. Contrasting a general belief, it has been observed that adipose mass strongly influences LV mass, particularly in women, especially when fat-free mass is relatively deficient. Thus, though blood pressure control is mandatory for prevention and reduction of LVH in obese hypertensive patients, without reduction of visceral adiposity regression of LVH is difficult. Future researches should be addressed on (1) assessing whether $\mathrm{LVH}$ resulting from alteration of body composition carries the same prognosis as pressure overload LVH; (2) defining tissue characterization of the hypertrophic heart in obese-hypertensive patients; (3) evaluating whether assessment of hemodynamic loading conditions and biological markers can help defining management of the association of obesity with hypertension.
\end{abstract}

Keywords: Obesity, Hypertension, Left ventricular mass, Body composition

\section{Background}

In this mini-review we will examine the impact of obesity in the hypertensive population, focusing on the common cardiovascular changes and interaction, leading to considerations on sex difference and body composition and potential influence on management (Fig. 1).

\section{Obesity as a comorbidity in arterial hypertension}

More than $80 \%$ of hypertensive patients present with additional risk factors, including glucose intolerance, hyperinsulinemia, lipid disorders (reduced HDL-cholesterol and increased LDL-cholesterol and triglycerides)

\footnotetext{
*Correspondence: simogi@unina.it

${ }^{1}$ Hypertension Research Center, Federico II University Hospital, Via S.

Pansini 5, Building 1,80131 Naples, Italy

Full list of author information is available at the end of the article
}

and obesity [1-4]. More than $50 \%$ of hypertensive patients present at least 2 of these comorbidities and, generally, one of those is obesity [4].

There is strong evidence that the prevalence of hypertension increases sharply with increasing body weight [2]. Scattered longitudinal analyses also suggest that obesity is an important risk factor also for incident hypertension, especially in women $[5,6]$.

Recently, the Southern Community Cohort Study, a large population-based survey, reported the probability of hypertension rising from $56 \%$ in overweight participants, to 2.5 fold in class I/II obesity, and up to 4.5 times in morbid obese participants [7]. This sharp progression of probability is also evident in kids and adolescents [8$10]$, though a significant decline might be observed in the past 10 years [11]. 


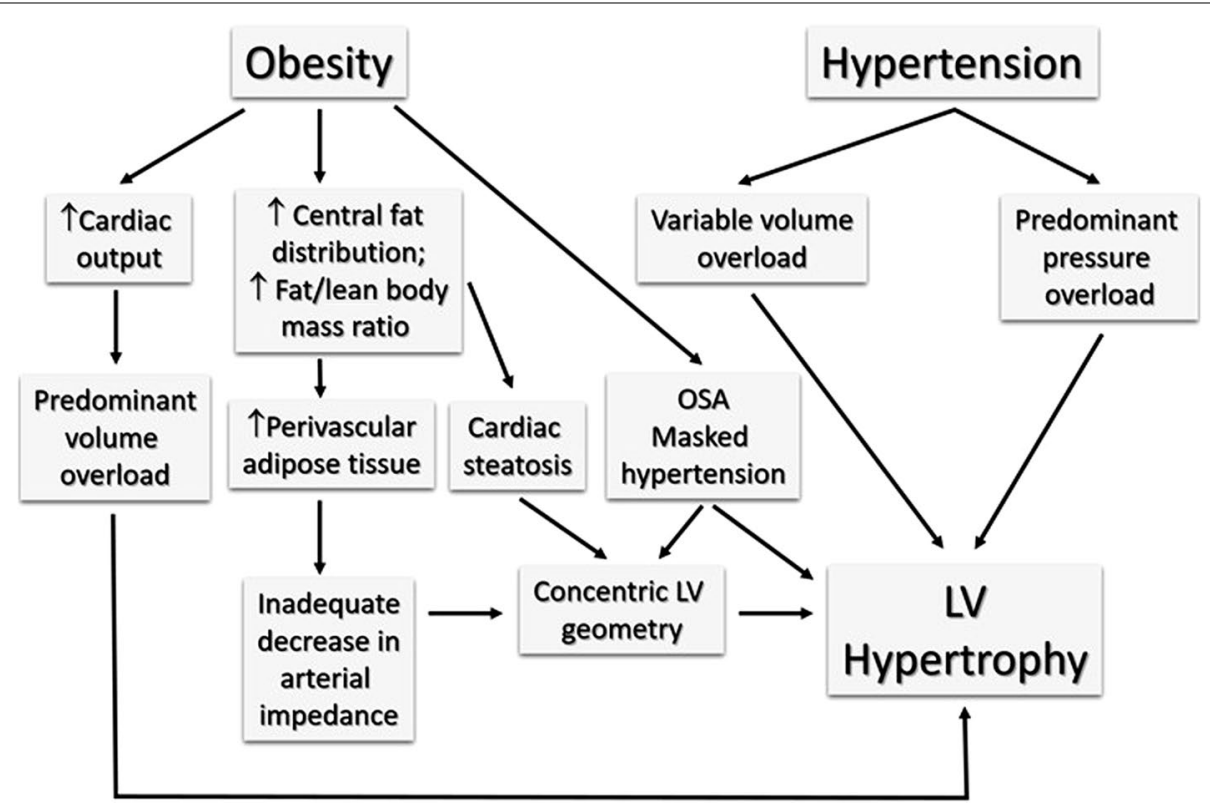

Fig. 1 Physiologic changes promoting common cardiovascular modifications in obesity and hypertension. OSA obstructive sleep apnea, LV left ventricular

In a Caribbean population based study [10], among 20235 -to-16 year-old public school students, the prevalence of hypertension was $13 \%$ in normal-weight individuals, raising to $23 \%$ in overweight and as much as $53 \%$ in obese subjects.

An important methodological issue, when assessing blood pressure in the obese patient, is the cuff size. Blood pressure measurement must take into account upper-arm circumference and the cuff size in both office and home setting [12]. Use of small cuff size causes overestimation of blood pressure and often increases the incidence of white coat or masked hypertension [13].

\section{Cardiovascular modifications of obesity}

Evaluation of obesity-related cardiovascular changes poses method problems, especially when normalization for body size is needed. The traditional use of body surface area (BSA) is inappropriate, because of geometric inconsistencies between BSA and LV mass, but also because body weight (and therefor fat mass) is included in the computation of BSA [14]. Thus using BSA produces a substantial underestimation of the prevalence of LV hypertrophy (LVH) in population with high prevalence of obesity [15]. Using of allometric signal of body height, obtained in a reference population [14] and recently confirmed in a different cohort study [16], nearly doubles the population risk attributable to LVH, especially when prevalence of obesity is high [17].
Observation of cardiovascular modifications of obesity during adolescence are particularly helpful to highlight the consistency of abnormalities of obesity with those found in the context of arterial hypertension.

In the young obese offspring participants of the Strong Heart Family Study cohort [18], although prevalence of occasional high BP was low (10\% in the obese sub-population), clear-cut LV hypertrophy (LVH) was progressively greater in overweight and obese adolescents compared to normal-weight individuals, paralleling the magnitude of adipose mass (Fig. 2). LV geometry was mainly eccentric [18]. In the HyperGEN registry [19], the impact of obesity, diabetes and dyslipidemia (labeled generically as «metabolic risk factors $\gg$ ) were assessed relatively to the probability of LVH in both normotensive and hypertensive subjects. The probability of LVH in normotensive participants with 1 or more metabolic risk factors was as high as the probability of LVH in hypertensive subjects without any of them, and was independently related to central fat distribution and associated «metabolic risk factors $\gg$. The association of metabolic risk factors with hypertension increases remarkably the probability of LVH.

The proportion of LV concentric geometry, the most deleterious LV geometric pattern [20], sharply raises during middle age $[21,22]$ and becomes the most frequent LV geometric patterns among obese individuals [23, 24]. Thus, the association of obesity with hypertension produces a combined pressure and volume overload, which 


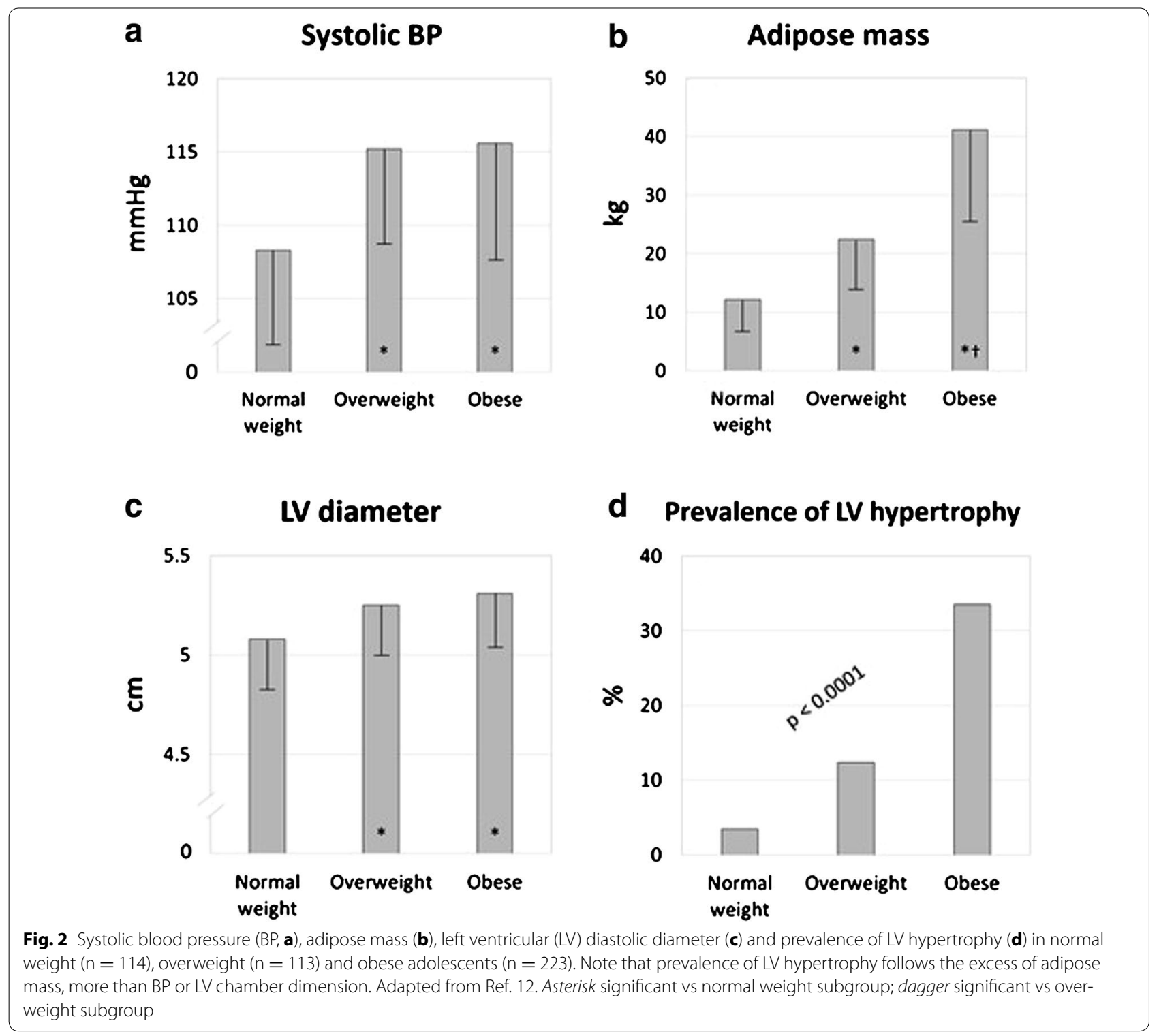

yields specific LV geometric abnormalities [20] and the most severe degrees of $\mathrm{LVH}$, similar to that reported for the hemodynamic overload caused by specific valvular heart disease producing combined volume and pressure overload [19] [25].

The traditional paradigm of cardiovascular modifications in obesity with hypertension has been that obese individuals mostly develop eccentric $\mathrm{LVH}$, due to the increased volume overload [26, 27]. However, this paradigm, is changing [28], because of the increasing evidence that concentric LV geometry is very prevalent in obese individuals [21, 22, 24, 29]. In a population sample of hypertensive New York employees [23], the combination of hypertension and obesity was associated with a greater prevalence of concentric LVH than in normal-weight participants. Woodiwiss et al. [29] studied a population sample of untreated hypertensive patients and found that obesity promotes LV concentric remodeling and hypertrophy rather than eccentric LVH. Similarly and more recently, Turkbey et al. [24] found that concentric LVH was the most frequent LV geometric pattern in obesity, using magnetic resonance imaging in the large population of the MESA study, forcing one to consider revising the prevalent viewpoint [28].

In obese patient, the increase in relative wall thickness (the most used index of concentricity) and LV mass is also typically associated with evidence of subclinical LV systolic dysfunction, especially when hypertension coexists, such as depressed midwall shortening, abnormal reduced tissue myocardial velocities, strain and strain 
rate $[30,31]$. In the presence of concentric LV geometry, ejection fraction is an imprecise marker of systolic function [32], because the cardiomyocyte contraction is amplified across the wall thickness by the interplay of cross-fiber thickening and shortening of differently aligned muscular fibers [33, 34].

Many mechanisms have been proposed to explain the association of obesity with hypertensive target organ damage, including enhanced sympathetic system activity, production of inflammatory cytokines and endothelial dysfunction [35-37]. These mechanisms are related to the circulatory and tissue conditions associated with obesity.

\section{Abnormal conditions associated with cardiovascular modifications in obesity Hemodynamic load}

Two conditions are frequent in obesity, potentially helping explaining the prevalent concentric LV geometry: severe obstructive sleep apnea (OSA) and masked hypertension.

OSA has been demonstrated to elicit concentric LV geometry [38], substantially due to the frequent pressure overload due to the phases of apnea and the consequent drop of $\mathrm{O}_{2}$ saturation [39]. OSA also causes a chronic mild inflammatory status, a characteristic frequently reported in the context of central obesity [40].

Another stimulus to continuous pressure overload is masked hypertension, reported to be more frequent in obesity [41]. The reasons of this association is not completely clear. Cardiac output is greater in obesity, in resting conditions, and daily activities might further increase output to a level that is not compensated by adequate decrease in both pulsatile and steady components of arterial impedance, to maintain normal blood pressure [42], mainly due to obesity associated endothelial dysfunction [43-45]. This abnormal adaptation generates a pressure overload superimposed to the "natural" volume overload pattern seen in obesity. Advanced glycation end-products and peri-vascular fat might contribute to the mismatch between flow output and vascular capacitance [46, 47].

In addition to the hemodynamic changes that help explaining prevalence of concentric LV geometry, there is also some evidence that increased sarcomere production is not the sole phenomenon to be involved in the increased myocardial mass occurring in obesity [48].

\section{Body composition}

A paradigm in the pathophysiology of obesity is that the increased LV mass is a function of the increased fat-free mass, a typical feature of increased body weight also among obese individuals $[49,50]$, whereas adipose mass has little influence [51, 52]. However, body composition has an important impact on LV geometry in hypertensive-obese individuals. When the visceral component of adipose mass is considered, a close correlation with LV mass becomes evident $[53,54]$, with differences between men and women.

On epidemiological scale, in women, the importance of adipose mass on variability of LV mass is as high as that of arterial hypertension [50], whereas fat-free mass is independently related to LV mass in both men and women. The "cardiac steatosis" also has functional consequences in women but not in men [55]. The statistical effect of adipose mass on variability of LV mass in women is interrelated to the visceral distribution, as indicated by the significant impact of waist-to-hip ratio (Fig. 3).

Adipose mass also influences LV geometry. In a clinical study involving lean, obese and former-obese individuals [56], LV relative wall thickness, a potent measure of concentric LV geometry, was closely related to adipose mass (mostly intra-abdominal), and not to lean body mass. This relation was even closer than the relation of relative wall thickness with systolic BP. Based on these findings, one might postulate that visceral fat contributes by non-hemodynamic pathways to the development of concentric LV geometry in obese individuals. If this postulate holds truth, one may speculate that in obese subjects with severe abnormalities of body composition (i.e. with excess body fat/fat-free mass deficiency), LVH and LV concentric geometry should be even more severe.

\section{Adipose mass and LV geometry}

We specifically studied the effect of fat mass in a special sub-population of obese individuals exhibiting a relative deficiency of fat-free mass and a consequent excess of adipose mass [54], a condition that is sometimes defined as «sarcopenic obesity» [57]. The identification of this condition is not easy because in obesity fatfree mass is always increased in absolute terms [49, 50, 58]. In the strong heart study cohort, a relative fat-free mass deficiency was found in $46 \%$ of the obese population, a characteristic that was substantially more frequent in women than in men. According to the old paradigm of LV mass only related to fat-free mass, lower LV mass could be expected in obese individuals with relative fatfree mass deficiency. In contrast, though formed by the $90 \%$ of women, this relatively «sarcopenic $\gg$ sub-group exhibited larger LV chamber size and greater LV mass (even when normalizing for fat-free mass) with a clear trend toward concentric LV geometry. This peculiar LV geometric pattern was associated with values of blood pressure similar to the subgroup of obese subjects with normal fat-free mass, the same prevalence of diagnosed arterial hypertension, but higher inflammatory markers. It is clear that in this context, the increased LV mass 


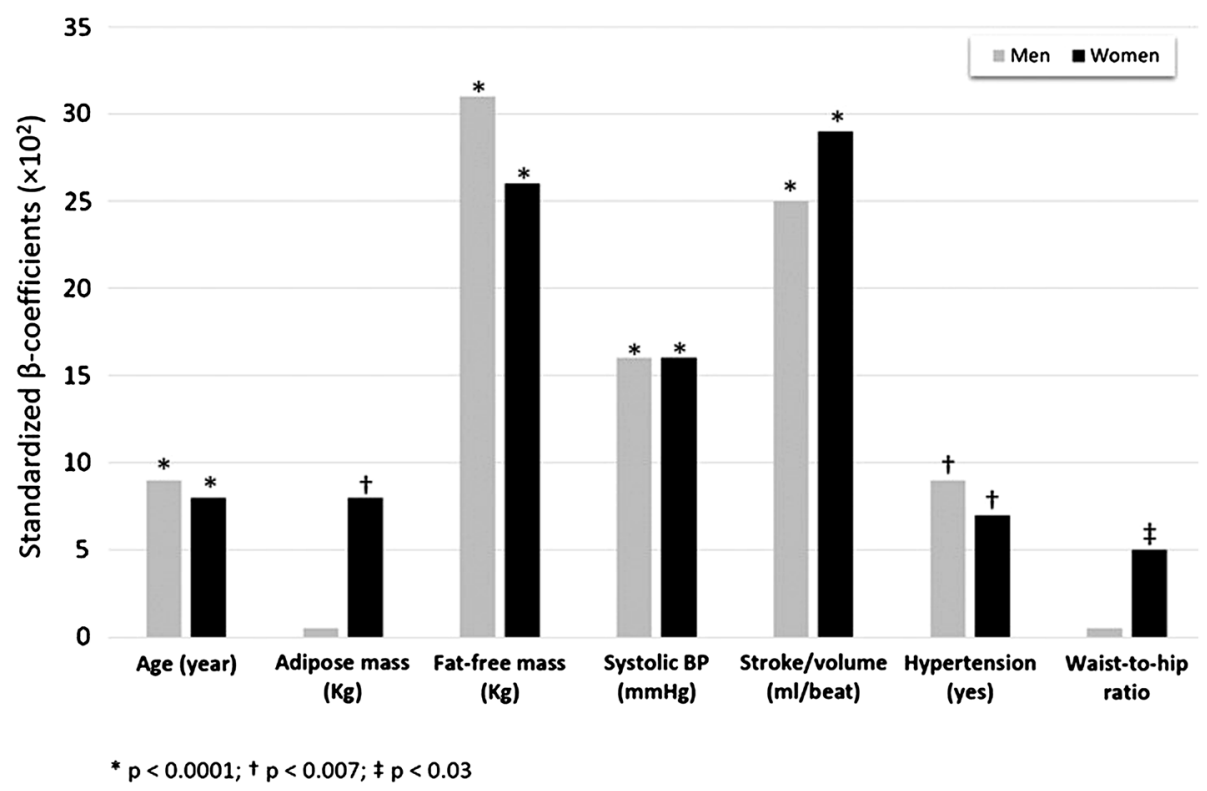

Fig. 3 Relative contribution of parameters associated with variance of LV mass index, by standardized $\beta$-coefficients obtained by multiple linear regression analysis in the cohort of the Strong Heart Study. Adipose mass together with waist-to-hip ratio exhibit significant association with LV mass index variance only in women. From Ref. [50]

cannot be considered as a pure consequence of biological mechanisms induced by the hemodynamic load.

There is a further demonstration that hypertensive LVH developing in obesity is unmatched with hemodynamic loading condition. When LV geometric adaptation is evaluated in relation to the need to sustain hemodynamic load, obesity is associated with excess of LV mass, in both men and women, relative to the magnitude of myocardial mass that would be adequate to sustain the individual hemodynamic load [50]. Women, in whom sarcopenia is much more prevalent, exhibit levels of excess of LV mass substantially greater than men, strongly suggesting, therefore, that there might be alterations in the normal myocardial structure associated with the increased LV mass. The complex of these findings forces to reconsider the old Virkow's definition of $\ll$ the fatty heart» [59].

There is strong evidence that overnutrition produces adipocyte infiltration in the liver, pancreas, kidney, muscles and heart, and triglycerides accumulate into the cells [60]. At the heart level, this has been directly demonstrated using cine-magnetic resonance imaging and a technique called «localized proton spectroscopy $\gg$, able to identify exactly the triglyceride peak. The amount of triglycerides in the myocardium is closely related to BMI and has been directly demonstrated in specimens using oil red O staining $[55,56,61]$. Thus, the measure of LV mass in obese individuals includes cell populations and cell components that are different from what measured in lean subjects. The increased amount of fat infiltrating the myocardium carries 2 important functional consequences, the overwhelming availability of fatty acids and the consequent increase in insulin resistance [62, 63]. The consequence of this biological alteration is a switch in the energy production, with the further reduction of carbohydrate oxidation and the overwhelming fatty acids oxidation which is a less efficient way to produce energy [64]. The reduced myocardial mechano-energetic efficiency related to fatty acid oxidation carries negative effects in terms of cardiovascular outcome and is substantially more prevalent in obesity [65].

Thus, the increased LV mass in obesity is related not only to the increased muscle component, which is elicited by the increased hemodynamic load. The expansion of myocardial tissue related to non-muscular components (adipocyte infiltration, fibrosis, cardiomyocyte thickening) $[60,61]$ helps understanding the tendency to more prevalent concentric LV geometry, as the ratio between fat and fat-free mass increases. Under this scenario, the concentric LV geometry related to obesity would not be a consequence of cardiomyocyte thickening due to parallel superimposition of sarcomeres, but rather infiltration of non-muscular components [48]. Superimposing arterial hypertension to this unfavorable structural pattern produces the greatest levels of LVH because of both hemodynamic (combined pressure and volume overload) and non-hemodynamic reasons (fat infiltration, inflammation). 


\section{Blood pressure control in the obese patient}

In general, the hemodynamic pattern typical of the combination of obesity and hypertension is characterized by increased intravascular volume component that should be taken into account when managing arterial hypertension [20].

Controlling blood pressure is difficult in the presence of obesity. In the Campania Salute Network, the probability to optimally control blood pressure decreases with increasing BMI, despite the greater number of medications used $[66,67]$. The frequency of increased BP despite aggressive therapy in the context of obesity is likely to be due to mechanisms related to the autocrine and paracrine activity of perivascular fat, namely the production of angiotensin II and aldosterone, making peculiar the origin of hypertension in obese individuals [68]. We also postulate that studying the characteristics of the hemodynamic load might help understanding a more pathophysiologic way to manage arterial hypertension in the presence of obesity, based on the combination between types of hemodynamic overload and metabolic abnormalities, as we have recently proposed [22].

Even in the presence of good control of BP, not necessarily LV mass follows the decrease in BP when obesity is present. In the HyperGEN registry, partial correction of metabolic abnormalities and high BP characterizing metabolic syndrome, but without reduction of central obesity, did not result in a corresponding lower LV mass [69], suggesting that a consistent reduction of LV mass cannot be achieved in this context without a program of weight reduction (Fig. 4).

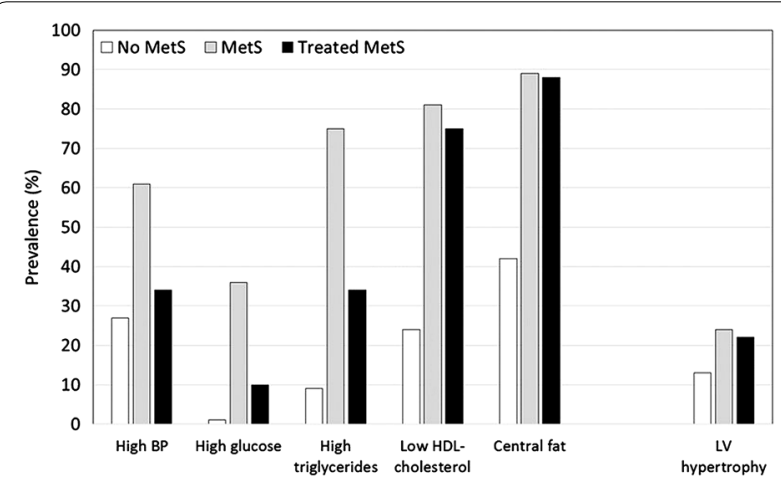

Fig. 4 Prevalence of single components of metabolic syndrome (MetS), according to the NCEP-ATPIII definition, in the participants in the HyprGEN study (from Ref. 47). Columns represents the prevalence in the sub-population without MetS (white) or with present MetS (grey) or with diagnosis of MetS, partially controlled by treatment of single components. Prevalence of all risk factors is significantly reduced in the managed MetS sub-group $(0.05<p<0.0001)$, except central fat. LV hypertrophy is not influenced by the control of those risk factors, including hypertension

\section{Weight loss and regression of cardiovascular abnormalities}

Dietary intervention and bariatric surgery are the mainstay for obesity treatment. Abnormal LV geometry and function can substantially improve after weight loss in both adults and adolescents. Weight loss is associated with reduction of LV hypertrophy in obese individuals $[70,71]$, an effect that is even more evident, compared with the effect of blood pressure reduction on reduction of LV mass $[49,72]$. In observational studies of high-risk hypertensive patients, a given decrease in blood pressure is less effective to reduce LV mass when obesity is present [73].

An extreme option is bariatric surgery, which is very effective to control the cluster of obesity-related cardiovascular risk factors, hypertension and diabetes (or insulin-resistance) [74]. In adults with morbid obesity, weight loss after bariatric surgery is associated with improvement of LV systolic function and normalization of LV geometry also due to the consistent reduction of systolic BP [75, 76]. After bariatric surgery, even adolescent obese subjects exhibit regression of LV hypertrophy and a trend toward normalization of LV concentric geometry [77].

\section{Current recommendations and need for research}

$\mathrm{LVH}$ is the most relevant marker of cardiovascular risk in arterial hypertension and current guidelines strongly recommend decrease LV mass. However, given the particularity of LVH in the combination of arterial hypertension with obesity, whether or not LVH has the same prognostic impact in both obese and non-obese hypertensive individuals is still unclear.

Current guidelines for arterial hypertension [78, 79] do not have specific suggestions for treatment of arterial hypertension and regression of $\mathrm{LVH}$ in the presence of obesity. Also, the recent recommendations for the management of obesity $[80,81]$, while strongly suggesting the study of body composition and highlighting the peculiarities of the combination of obesity with hypertension, do not have clear indication on management.

We think that efforts should be oriented to characterize:

1. Whether LVH has the same pathophysiological meaning and, therefore, prognostic impact in both obese and non-obese men and women;

2. The tissue characterization of the hypertrophic heart in obese-hypertensive patients, a possibility emerging from new technologies applied to nuclear magnetic resonance [82, 83];

3. Whether extensive assessment of hemodynamic loading conditions and biological markers can help defining management of the association of obesity 
with hypertension even beyond the crude intervention on loading conditions.

\section{Conclusions}

Obesity and hypertension are closely linked conditions. Obesity exaggerates LV response to increased hemodynamic load in large part throughout the effect of nonhemodynamic mechanisms elicited by visceral adiposity. Fat mass is as important as, and perhaps more important than, fat-free mass to promote increase in LV mass in visceral obesity, which is especially evident in women, related to their body composition. Body composition is likely to be a key factor in determining LV geometry in the presence of obesity and is at the basis of the paradoxical sex-difference found in LV adaptation to arterial hypertension. Effectively controlling BP and reducing hypertensive LVH is difficult without managing obesity. Research should be implemented to find more adequate approach to manage this frequent combination.

\section{Authors' contributions}

GdS conceived the manuscript, CM coordinate to draft the manuscript, RI, $M A L, L A F$ helped to draft the manuscript, gave conceptual help and prepared the figures. All authors read and approved the final manuscript.

\section{Author details}

${ }^{1}$ Hypertension Research Center, Federico II University Hospital, Via S. Pansini 5, Building 1, 80131 Naples, Italy. ${ }^{2}$ Department of Translational Medical Sciences, Federico II University Hospital, Naples, Italy. ${ }^{3}$ Department of Advanced Medical Bioscience, Federico II University Hospital, Naples, Italy.

\section{Acknowledgements}

None. 2015.

This review is realized based on the conference given at the ESC Congress

\section{Competing interests}

The authors declare that they have no competing interests.

\section{Availability of data and materials}

Authors do not wish to share their data. All the data published in original papers belongs to Hypertension Research Center, University of Naples Federico II.

\section{Funding}

All the authors do not receive any funding related to this manuscript.

Received: 3 August 2016 Accepted: 22 November 2016

Published online: 30 November 2016

\section{References}

1. Third Report of the National Cholesterol Education Program. (NCEP) Expert Panel on Detection, Evaluation, and Treatment of High Blood Cholesterol in Adults (Adult Treatment Panel III) final report. Circulation. 2002;106:3143-421.

2. Kannel WB, Brand N, Skinner JJ Jr, Dawber TR, McNamara PM. The relation of adiposity to blood pressure and development of hypertension. The Framingham study. Ann Intern Med. 1967;67:48-59.

3. Landsberg L, Aronne LJ, Beilin L, Burke V, Igel LI, Lloyd-Jones D, Sowers J. Obesity-related hypertension: pathogenesis, cardiovascular risk, and treatment. J Clin Hypertens. 2013;15:14-33.
4. Kannel WB. Risk stratification in hypertension: new insights from the Framingham Study. Am J Hypertens. 2000;13:3S-10S.

5. Fujita M, Hata A. Sex and age differences in the effect of obesity on incidence of hypertension in the Japanese population: a large historical cohort study. J Am Soc Hypertens. 2014;8:64-70.

6. de Simone G, Devereux RB, Chinali M, Roman MJ, Best LG, Welty TK, Lee ET, Howard BV. Risk factors for arterial hypertension in adults with initial optimal blood pressure: the Strong Heart Study. Hypertension. 2006:47:162-7.

7. Sampson UK, Edwards TL, Jahangir E, Munro H, Wariboko M, Wassef MG, Fazio S, Mensah GA, Kabagambe EK, Blot WJ, Lipworth L. Factors associated with the prevalence of hypertension in the southeastern United States: insights from 69,211 blacks and whites in the Southern Community Cohort Study. Circ Cardiovasc Qual Outcomes. 2014;7:33-54.

8. Koebnick C, Black MH, Wu J, Martinez MP, Smith N, Kuizon B, Cuan D, Young DR, Lawrence JM, Jacobsen SJ. High blood pressure in overweight and obese youth: implications for screening. J Clin Hypertens (Greenwich). 2013;15:793-805.

9. Sorof J, Daniels S. Obesity hypertension in children: a problem of epidemic proportions. Hypertension. 2002;40:441-7.

10. Schwiebbe L, Talma H, Renders C, Visser R, Kist-van Holthe JE, Hirasing RA. High prevalence of hypertension in obese children in the Caribbean. Paediatr Int Child Health. 2012;32:204-7.

11. Koebnick C, Mohan YD, Li X, Young DR. Secular trends of overweight and obesity in young Southern Californians 2008-2013. J Pediatr. 2015:167:1264-71.

12. Wittenberg C, Erman A, Sulkes J, Abramson E, Boner G. Which cuff size is preferable for blood pressure monitoring in most hypertensive patients? J Hum Hypertens. 1994;8:819-22.

13. Mourad JJ, Lopez-Sublet M, Aoun-Bahous S, Villeneuve F, Jaboureck O, Dourmap-Collas C, Denolle T, Fourcade J, Baguet JP. Impact of miscuffing during home blood pressure measurement on the prevalence of masked hypertension. Am J Hypertens. 2013;26:1205-9.

14. de Simone G, Daniels SR, Devereux RB, Meyer RA, Roman MJ, de Divitiis $\mathrm{O}$, Alderman $\mathrm{MH}$. Left ventricular mass and body size in normotensive children and adults: assessment of allometric relations and impact of overweight. J Am Coll Cardiol. 1992;20:1251-60.

15. Palmieri V, de Simone G, Arnett DK, Bella JN, Kitzman DW, Oberman A, Hopkins PN, Province MA, Devereux RB. Relation of various degrees of body mass index in patients with systemic hypertension to left ventricular mass, cardiac output, and peripheral resistance (The Hypertension Genetic Epidemiology Network Study). Am J Cardiol. 2001;88:1163-8.

16. Kuznetsova T, Haddad F, Tikhonoff V, Kloch-Badelek M, Ryabikov A, Knez J, Malyutina S, Stolarz-Skrzypek K, Thijs L, Schnittger I, Wu JC, Casiglia E, Narkiewicz K, Kawecka-Jaszcz K, Staessen JA. Impact and pitfalls of scaling of left ventricular and atrial structure in population-based studies. J Hypertens. 2016;34:1186-94.

17. de Simone G, Kizer JR, Chinali M, Roman MJ, Bella JN, Best LG, Lee ET, Devereux RB. Normalization for body size and population-attributable risk of left ventricular hypertrophy: the Strong Heart Study. Am J Hypertens. 2005;18:191-6

18. Chinali M, de Simone G, Roman MJ, Lee ET, Best LG, Howard BV, Devereux RB. Impact of obesity on cardiac geometry and function in a population of adolescents: the Strong Heart Study. J Am Coll Cardiol. 2006;47:2267-73

19. de Simone G, Palmieri V, Bella JN, Celentano A, Hong Y, Oberman A, Kitzman DW, Hopkins PN, Arnett DK, Devereux RB. Association of left ventricular hypertrophy with metabolic risk factors: the HyperGEN study, J Hypertens. 2002;20:323-31.

20. de Simone G, Izzo R, Aurigemma GP, De MM, Rozza F, Trimarco V, Stabile E, De Luca N, Trimarco B. Cardiovascular risk in relation to a new classification of hypertensive left ventricular geometric abnormalities. J Hypertens. 2015:33:745-54.

21. Aurigemma GP, de Simone G, Fitzgibbons TP. Cardiac remodeling in obesity. Circ Cardiovasc Imaging. 2013;6:142-52.

22. de Simone G, Izzo R, De Luca N, Gerdts E. Left ventricular geometry in obesity: is it what we expect? Nutr Metab Cardiovasc Dis. 2013;23:905-12.

23. de Simone G, Devereux RB, Roman MJ, Alderman MH, Laragh JH. Relation of obesity and gender to left ventricular hypertrophy in normotensive and hypertensive adults. Hypertension. 1994;23:600-6. 
24. Turkbey EB, McClelland RL, Kronmal RA, Burke GL, Bild DE, Tracy RP, Arai $A E$, Lima JA, Bluemke DA. The impact of obesity on the left ventricle: the Multi-Ethnic Study of Atherosclerosis (MESA). JACC Cardiovasc Imaging. 2010;3:266-74.

25. Carabello BA. The relationship of left ventricular geometry and hypertrophy to left ventricular function in valvular heart disease. J Heart Valve Dis. 1995:4(Suppl 2):S132-8.

26. Alpert MA, Hashimi MW. Obesity and the heart. Am J Med Sci. 1993;306:117-23.

27. Nadruz W. Myocardial remodeling in hypertension. J Hum Hypertens. 2015:29:1-6.

28. Litwin SE. Cardiac remodeling in obesity: time for a new paradigm. JACC Cardiovasc Imaging. 2010;3:275-7

29. Woodiwiss AJ, Libhaber CD, Majane OH, Libhaber E, Maseko M, Norton GR. Obesity promotes left ventricular concentric rather than eccentric geometric remodeling and hypertrophy independent of blood pressure. Am J Hypertens. 2008;21:1144-51.

30. Ballo P, Mondillo S, Guerrini F, Barbati R, Picchi A, Focardi M. Midwall mechanics in physiologic and hypertensive concentric hypertrophy. J Am Soc Echocardiogr. 2004;17:418-27.

31. Wong CY, O'Moore-Sullivan T, Leano R, Byrne N, Beller E, MarwickTH. Alterations of left ventricular myocardial characteristics associated with obesity. Circulation. 2004;110:3081-7.

32. de Simone G, Devereux RB, Celentano A, Roman MJ. Left ventricular chamber and wall mechanics in the presence of concentric geometry. $J$ Hypertens. 1999;17:1001-6.

33. de Simone G, Devereux RB. Rationale of echocardiographic assessment of left ventricular wall stress and midwall mechanics in hypertensive heart disease. Eur J Echocardiogr. 2002;3:192-8.

34. Rademakers FE, Rogers WJ, Guier WH, Hutchins GM, Siu CO, Weisfeldt ML, Weiss JL, Shapiro EP. Relation of regional cross-fiber shortening to wall thickening in the intact heart. Three-dimensional strain analysis by NMR tagging. Circulation. 1994;89:1174-82.

35. Grassi G, Cattaneo BM, Seravalle G, Colombo M, Cavagnini F, Mancia G. Obesity and the sympathetic nervous system. Blood Press Suppl. 1996;1:43-6.

36. Kim JA, Montagnani M, Koh KK, Quon MJ. Reciprocal relationships between insulin resistance and endothelial dysfunction: molecular and pathophysiological mechanisms. Circulation. 2006;113:1888-904.

37. Ziccardi P, Nappo F, Giugliano G, Esposito K, Marfella R, Cioffi M, D'Andrea F, Molinari AM, Giugliano D. Reduction of inflammatory cytokine concentrations and improvement of endothelial functions in obese women after weight loss over one year. Circulation. 2002;105:804-9.

38. Cioffi G, Russo TE, Stefenelli C, Selmi A, Furlanello F, Cramariuc D, Gerdts E, de Simone S. Severe obstructive sleep apnea elicits concentric left ventricular geometry. J Hypertens. 2010;28:1074-82.

39. Dewan NA, Nieto FJ, Somers VK. Intermittent hypoxemia and OSA: implications for comorbidities. Chest. 2015;147:266-74.

40. Shamsuzzaman AS, Winnicki M, Lanfranchi P, Wolk R, Kara T, Accurso V, Somers VK. Elevated C-reactive protein in patients with obstructive sleep apnea. Circulation. 2002;105:2462-4.

41. Kotsis V, Stabouli S, Toumanidis S, Papamichael C, Lekakis J, Germanidis G, Hatzitolios A, Rizos Z, Sion M, Zakopoulos N. Target organ damage in "white coat hypertension" and "masked hypertension". Am J Hypertens. 2008:21:393-9.

42. Kotsis V, Stabouli S, Toumanidis S, Tsivgoulis G, Rizos Z, Trakateli C, Zakopoulos N, Sion M. Obesity and daytime pulse pressure are predictors of left ventricular hypertrophy in true normotensive individuals. J Hypertens. 2010;28:1065-73.

43. Arcaro G, Zamboni M, Rossi L, Turcato E, Covi G, Armellini F, Bosello O, Lechi A. Body fat distribution predicts the degree of endothelial dysfunction in uncomplicated obesity. Int J Obes Relat Metab Disord. 1999;23:936-42

44. Goodfellow J, Owens D, Henderson A. Cardiovascular syndromes X, endothelial dysfunction and insulin resistance. Diabetes Res Clin Pract. 1996;31(Suppl):S163-71.

45. Picchi A, Gao X, Belmadani S, Potter BJ, Focardi M, Chilian WM, Zhang C. Tumor necrosis factor-\{alpha\} induces endothelial dysfunction in the prediabetic metabolic syndrome. Circ Res. 2006;99:69-77.

46. Britton KA, Fox CS. Perivascular adipose tissue and vascular disease. Clin Lipidol. 2011;6:79-91.
47. Stirban A, Gawlowski T, Roden M. Vascular effects of advanced glycation endproducts: clinical effects and molecular mechanisms. Mol Metab. 2014;3:94-108.

48. Abel ED, Litwin SE, Sweeney G. Cardiac remodeling in obesity. Physiol Rev. 2008;88:389-419.

49. Kardassis D, Bech-Hanssen O, Schonander M, Sjostrom L, Karason K. The influence of body composition, fat distribution, and sustained weight loss on left ventricular mass and geometry in obesity. Obesity (Silver Spring). 2012;20:605-11.

50. de Simone G, Devereux RB, Chinali M, Roman MJ, Barac A, Panza JA, Lee ET, Howard BV. Sex differences in obesity-related changes in left ventricular morphology: the Strong Heart Study. J Hypertens. 2011;29:1431-8.

51. Bella JN, Devereux RB, Roman MJ, O'Grady MJ, Welty TK, Lee ET, Fabsitz RR, Howard BV. Relations of left ventricular mass to fat-free and adipose body mass: the strong heart study. Circulation. 1998;98:2538-44.

52. Whalley GA, Gamble GD, Doughty RN, Culpan A, Plank L, MacMahon S, Sharpe N. Left ventricular mass correlates with fat-free mass but not fat mass in adults. J Hypertens. 1999;17:569-74.

53. Avelar E, Cloward TV, Walker JM, Farney RJ, Strong MH, Pendleton RC, Segerson N, Adams TD, Gress RE, Hunt SC, Litwin SE. Left ventricular hypertrophy in severe obesity: interactions between systolic blood pressure, nocturnal hypoxemia and increasing body mass. Hypertension. 2007:49:34-9.

54. de Simone G, Pasanisi F, Ferrara AL, Roman MJ, Lee ET, Contaldo F, Howard BV, Devereux RB. Relative fat-free mass deficiency and left ventricular adaptation to obesity: the Strong Heart Study. Int J Cardiol. 2013;168:729-33.

55. Liu CY, Bluemke DA, Gerstenblith G, Zimmerman SL, Li J, Zhu H, Lai S, Lai $H$. Myocardial steatosis and its association with obesity and regional ventricular dysfunction: evaluated by magnetic resonance tagging and $1 \mathrm{H}$ spectroscopy in healthy African Americans. Int J Cardiol. 2014;172:381-7.

56. Relling DP, Esberg LB, Fang CX, Johnson WT, Murphy EJ, Carlson EC, Saari JT, Ren J. High-fat diet-induced juvenile obesity leads to cardiomyocyte dysfunction and upregulation of Foxo3a transcription factor independent of lipotoxicity and apoptosis. J Hypertens. 2006;24:549-61.

57. Stenholm S, Harris TB, Rantanen T, Visser M, Kritchevsky SB, Ferrucci L. Sarcopenic obesity: definition, cause and consequences. Curr Opin Clin Nutr Metab Care. 2008;11:693-700.

58. Forbes GB, Welle SL. Lean body mass in obesity. Int J Obes. 1983;7:99-107

59. Die Virchow R. Zellularpathologie und ihre Begründung auf physiologische und pathologische Gewebelehre. Berlin: Verlag von A. Hirschwald; 1858.

60. McGavock JM, Victor RG, Unger RH, Szczepaniak LS. Adiposity of the heart, revisited. Ann Intern Med. 2006;144:517-24.

61. Szczepaniak LS, Victor RG, Orci L, Unger RH. Forgotten but not gone: the rediscovery of fatty heart, the most common unrecognized disease in America. Circ Res. 2007;101:759-67.

62. Koutsari $C$, Jensen MD. Thematic review series: patient-oriented research. Free fatty acid metabolism in human obesity. J Lipid Res. 2006;47:1643-50.

63. Duncan JG. Mitochondrial dysfunction in diabetic cardiomyopathy. Biochim Biophys Acta. 2011;1813:1351-9.

64. Lopaschuk GD, Folmes CD, Stanley WC. Cardiac energy metabolism in obesity. Circ Res. 2007;101:335-47

65. de Simone G, Izzo R, Losi MA, Stabile E, Rozza F, Canciello G, Mancusi C, Trimarco V, De Luca N, Trimarco B. Depressed myocardial energetic efficiency is associated with increased cardiovascular risk in hypertensive left ventricular hypertrophy. J Hypertens. 2016;34:1846-53.

66. De Marco M, de Simone G, Izzo R, Mancusi C, Sforza A, Giudice R, Trimarco $B$, De Luca N. Classes of antihypertensive medications and blood pressure control in relation to metabolic risk factors. J Hypertens. 2012;30:188-93.

67. Arcucci O, de Simone G, Izzo R, Rozza F, Chinali M, Rao MA, Bodenizza C, De Luca N, Trimarco B. Association of suboptimal blood pressure control with body size and metabolic abnormalities. J Hypertens. 2007;25:2296-300.

68. Villacorta $L$, Chang $L$. The role of perivascular adipose tissue in vasoconstriction, arterial stiffness, and aneurysm. Horm Mol Biol Clin Investig. 2015;21:137-47.

69. de Simone G, Arnett DK, Chinali M, De MM, Rao DC, Kraja AT, Hunt SC, Devereux RB. Partial normalization of components of metabolic syndrome does not influence prevalent echocardiographic abnormalities: the HyperGEN study. Nutr Metab Cardiovasc Dis. 2013;23:38-45. 
70. Himeno E, Nishino K, Nakashima Y, Kuroiwa A, Ikeda M. Weight reduction regresses left ventricular mass regardless of blood pressure level in obese subjects. Am Heart J. 1996;131:313-9.

71. Alpert MA, Terry BE, Kelly DL. Effect of weight loss on cardiac chamber size, wall thickness and left ventricular function in morbid obesity. Am J Cardiol. 1985;55:783-6.

72. Karason K, Wallentin I, Larsson B, Sjostrom L. Effects of obesity and weight loss on left ventricular mass and relative wall thickness: survey and intervention study. BMJ. 1997;315:912-6.

73. de Simone G, Okin PM, Gerdts E, Olsen MH, Wachtell K, Hille DA, Dahlöf B, Kjeldsen SE, Devereux RB. Clustered metabolic abnormalities blunt regression of hypertensive left ventricular hypertrophy: the LIFE study. Nutr Metab Cardiovasc Dis. 2009;19:634-40.

74. Ricci C, Gaeta M, Rausa E, Macchitella Y, Bonavina L. Early impact of bariatric surgery on type II diabetes, hypertension, and hyperlipidemia: a systematic review, meta-analysis and meta-regression on 6587 patients. Obes Surg. 2014;24:522-8.

75. Hsuan CF, Huang CK, Lin JW, Lin LC, Lee TL, Tai CM, Yin WH, Tseng WK, Hsu KL, Wu CC. The effect of surgical weight reduction on left ventricular structure and function in severe obesity. Obesity (Silver Spring). 2010;18:1188-93.

76. Damiano S, De MM, Del GF, Contaldo F, Gerdts E, de Simone G, Pasanisi F. Effect of bariatric surgery on left ventricular geometry and function in severe obesity. Obes Res Clin Pract. 2012;6:175-262.

77. Ippisch HM, Inge TH, Daniels SR, Wang B, Khoury PR, Witt SA, Glascock BJ, Garcia VF, Kimball TR. Reversibility of cardiac abnormalities in morbidly obese adolescents. J Am Coll Cardiol. 2008;51:1342-8.

78. Mancia G, De Backer G, Dominiczak A, Cifkova R, Fagard R, Germano G, Grassi G, Heagerty AM, Kjeldsen SE, Laurent S, Narkiewicz K, Ruilope L, Rynkiewicz A, Schmieder RE, Boudier HA, Zanchetti A, Vahanian A, Camm J, De Caterina R, Dean V, Dickstein K, Filippatos G, Funck-Brentano C, Hellemans I, Kristensen SD, McGregor K, Sechtem U, Silber S, Tendera M, Widimsky P, Zamorano JL, Erdine S, Kiowski W, Agabiti-Rosei E, Ambrosioni E, Lindholm LH, Viigimaa M, Adamopoulos S, Agabiti-Rosei E, Ambrosioni E, Bertomeu V, Clement D, Erdine S, Farsang C, Gaita D, Lip G, Mallion JM, Manolis AJ, Nilsson PM, O'Brien E, Ponikowski P, Redon J, Ruschitzka F, Tamargo J, van Zwieten P, Waeber B, Williams B. 2007 Guidelines for the Management of arterial hypertension: the Task Force for the Management of Arterial Hypertension of the European Society of Hypertension (ESH) and of the European Society of Cardiology (ESC). J Hypertens. 2007;25:1105-87.
79. James PA, Oparil S, Carter BL, Cushman WC, Dennison-Himmelfarb C, Handler J, Lackland DT, LeFevre ML, MacKenzie TD, Ogedegbe O, Smith SC Jr, Svetkey LP, Taler SJ, Townsend RR, Wright JT Jr, Narva AS, Ortiz E. 2014 evidence-based guideline for the management of high blood pressure in adults: report from the panel members appointed to the Eighth Joint National Committee (JNC 8). JAMA. 2014;311:507-20.

80. Poirier P, Giles TD, Bray GA, Hong Y, Stern JS, Pi-Sunyer FX, Eckel RH. Obesity and cardiovascular disease: pathophysiology, evaluation, and effect of weight loss: an update of the 1997 American Heart Association Scientific Statement on Obesity and Heart Disease from the Obesity Committee of the Council on Nutrition, Physical Activity, and Metabolism. Circulation. 2006;113:898-918.

81. YumukV, Tsigos C, Fried M, Schindler K, Busetto L, Micic D, Toplak H. European guidelines for obesity management in adults. Obes Facts. 2015;8:402-24.

82. Nelson MD, Victor RG, Szczepaniak EW, Simha V, Garg A, Szczepaniak LS. Cardiac steatosis and left ventricular hypertrophy in patients with generalized lipodystrophy as determined by magnetic resonance spectroscopy and imaging. Am J Cardiol. 2013;112:1019-24.

83. Goodpaster BH, Stenger VA, Boada F, McKolanis T, Davis D, Ross R, Kelley DE. Skeletal muscle lipid concentration quantified by magnetic resonance imaging. Am J Clin Nutr. 2004;79:748-54.

\section{Submit your next manuscript to BioMed Central and we will help you at every step:}

- We accept pre-submission inquiries

- Our selector tool helps you to find the most relevant journal

- We provide round the clock customer support

- Convenient online submission

- Thorough peer review

- Inclusion in PubMed and all major indexing services

- Maximum visibility for your research

Submit your manuscript at www.biomedcentral.com/submit
() BioMed Central 